\title{
Associations of alcohol consumption with diabetes mellitus and impaired fasting glycemia among middle-aged and elderly Chinese
}

\author{
Chen Liu, Zhijie Yu*, Huaixing Li, Jing Wang, Liang Sun, Qibin Qi, Xu Lin
}

\begin{abstract}
Background: The U-shaped relationship between alcohol consumption and diabetes mellitus was observed among western populations. However, few studies have systematically evaluated the association in Chinese. We aimed to investigate the associations of alcohol consumption with diabetes mellitus and impaired fasting glycemia (IFG) among middle-aged and elderly Chinese.
\end{abstract}

Methods: We examined 1,458 men and 1,831 women aged 50 to 70 from Beijing and Shanghai China in a crosssectional survey. Fasting glucose, adipokines and markers of inflammation were measured. Macronutrients and alcohol consumption were assessed with standardized questionnaires.

Results: Compared with abstainers, alcohol consumption was associated with a decreased risk of having diabetes mellitus in women (OR: $0.41,95 \% \mathrm{Cl}: 0.22-0.78$ ) after controlling for socio-demographic factors, physical activity, smoking, family income, family history of cardiovascular disease or diabetes, macronutrients intake, body mass index, and markers of inflammation and adipokines. In men, both low and high alcohol consumptions were associated with increased risks of having combined diabetes and IFG (ORs 1.36 [95\%Cl: 1.02-1.82] and 1.50 [95\%Cl: 1.04-2.15], respectively]. In the multivariable stratified analyses among men, moderate drinkers who had drinking days of $\geq 5$ days/week had a deceased likelihood (OR: 0.61,95\%Cl: 0.37-0.98) and liquor drinkers had an increased likelihood (OR: 1.47, 95\%Cl: 1.09-1.98) of having combined diabetes and IFG respectively, compared with the abstainers.

Conclusions: An approximately J-shaped association was observed between alcohol consumption and combined diabetes and IFG among men compared with abstainers in Chinese. Whether moderate alcohol intake could help decrease diabetic risk among Chinese people warrants further investigation.

\section{Background}

A rapid increase in the prevalence of diabetes mellitus has become one of the major public health challenges in China, with approximately 92.4 million people having diabetes [1]. Unhealthy diet and sedentary lifestyle certainly are the major determiner in diabetes epidemic. As one of the important lifestyle factors, alcohol drinking showed a U-shaped association with the risk of diabetes mellitus among western populations, with the lowest risk being observed among individuals with moderate

\footnotetext{
* Correspondence: zjyu@sibs.ac.cn; xlin@sibs.ac.cn

Key Laboratory of Nutrition and Metabolism, Institute for Nutritional Sciences, Shanghai Institutes for Biological Sciences, Chinese Academy of Sciences and Graduate School of the Chinese Academy of Sciences, Shanghai, China
}

alcohol intake [2,3]. However, contradictory findings were reported from other studies [4,5]. The inconsistency might be attributable to the differences in beverage types, drinking frequency and dietary factors. Moreover, it is uncertain whether and to what extent that genetic backgrounds as well as lifestyle factors influence the association between alcohol intake and metabolic outcomes among difference ethical populations. So far, most of studies have been conducted among western populations and only one study investigated the relationship between alcohol intake and fasting glucose in Guangzhou, a southern city of China [6]. Given the substantial variations in lifestyles and disease patterns among peoples living in different geographic 
locations in China, more studies based on a representative sample of Chinese people are definitely warranted.

A large body of evidence revealed that the protective effect of moderate alcohol consumption on diabetes might be explained by the improvement of insulin sensitivity [7]. Meanwhile, some studies also documented strong link of alcohol consumption with adipokines and markers of inflammation $[8,9]$, which have been suggested to play important roles in the pathogenesis of diabetes $[10,11]$. However, the mediate effects of these cytokines on association between alcohol and diabetes have not been well studied in large populations.

The primary aim of this study was to investigate the associations of alcohol consumption with diabetes mellitus and impaired fasting glycemia (IFG) among middleaged and elderly populations living in Beijing (north) and Shanghai (south) China. Furthermore, we also explored the potential modifying effects of drinking frequency, beverage type, as well as adipokines, and markers of inflammation on the association.

\section{Methods}

\section{Study population}

The "Nutrition and Health of Aging Population in China" study, is a population-based cross-sectional survey conducted among people aged 50 to 70 years in Beijing and Shanghai China [12]. The study was implemented simultaneously in both geographic locations from March to June 2005. A multistage sampling method was used to recruit the participants from Beijing and Shanghai. Two urban districts and one rural district in both cities were chosen and the eligible candidates listed in the residential registration record were selected randomly. All participants were provided a written informed consent and the Institutional Review Board of the Institute for Nutritional Sciences approved the study protocol. A total of 3289 participants $(1,458$ men and 1,831 women) were successfully recruited for the present analyses.

All subjects were interviewed in person by trained physicians or public health workers. Data of sociodemographic information, lifestyle variables and health status were collected, by using standardized questionnaires. Dietary intakes during the past year were estimated from a 74 food item Food Frequency Questionnaire (FFQ) validated by Zhao et al. [13]. Total intakes of fat, carbohydrate, protein, fiber and energy (without energy from alcohol) were calculated according to the Chinese Food Composition Table 2004 [14].

\section{Assessments of alcohol consumption}

The information of alcohol consumption was obtained using a standardized questionnaire, which included drinking frequency, average monthly intake of each type of beverage (beer, wine, hard liquor $[>38 \% \mathrm{v} / \mathrm{v}]$ and light liquor $[\leq 38 \% \mathrm{v} / \mathrm{v}])$. Daily alcohol intake was calculated in grams by summing up monthly ethanol intake of each type of beverage and then divided by 30.5 with the following content: $50 \mathrm{ml}$ of hard liquor, $21.85 \mathrm{~g}$; 50 $\mathrm{ml}$ of light liquor, $15.75 \mathrm{~g}$; one $640 \mathrm{ml}$-bottle of beer, $31.36 \mathrm{~g}$ and $50 \mathrm{ml}$ of wine, $5.2 \mathrm{~g}$ according to the Chinese Food Composition Table 2004 [14].

Male drinkers were categorized into three groups: light (0.1-19.9 g/d), moderate (20.0-39.9 g/d) and heavy drinkers $(\geq 40.0 \mathrm{~g} / \mathrm{d})$, and were further grouped based on varieties and frequency of alcohol consumed. Liquor drinkers were defined for those consuming more liquor than other types of alcoholic beverage, whereas nonliquor drinker were defined for those having alcoholic beverage predominately other than liquor. Due to limited female alcohol drinkers $(\mathrm{n}=179)$, women were classified into abstainers and drinkers $(>0.1 \mathrm{~g} / \mathrm{d})$ in our study.

\section{Anthropometric measurements and laboratory methods}

All study participants were invited to have a physical examination at the community clinics. Anthropometric data and fasting blood samples were collected by trained medical professional using a standardized protocol. Body weight, height, waist circumference and blood pressure were measured. Body mass index (BMI) was calculated as weight $(\mathrm{kg}) /$ height $(\mathrm{m})^{2}$. The measurements of the plasma levels of fasting glucose, insulin, glycated haemoglobin A1c (HbA1C), high-density lipoprotein cholesterol (HDL-C), low-density lipoprotein cholesterol (LDL-C), triglyceride, C-reactive protein (CRP), interleukin-6 (IL-6), ferritin, retinol binding protein 4 (RBP4), adiponectin and plasminogen activator inhibitor type-1 (PAI-1) have been described previously [15]. HOMA-S and HOMA-B were calculated by the homeostasis model using Levy's computer model [16]. Diabetes mellitus including both type 1 and type 2 diabetes was defined as fasting glucose $\geq 7.0 \mathrm{mmol} / \mathrm{L}$ or diagnosed diabetes previously or received glucose-lowering therapy [17]. Combined diabetes and IFG was defined as fasting glucose $>5.6 \mathrm{mmol} / \mathrm{L}$ or diagnosed diabetes previously or received glucose-lowering therapy.

\section{Statistic analysis}

Forty-two individuals with acute inflammation (CRP $\geq 10.0 \mathrm{mg} / \mathrm{L}$ ) were excluded, leaving 3,247 individuals (1,435 men and 1,812 women) for the present analyses. When using IL-6, adiponectin and PAI-1 for further analyses, another 93 individuals (36 men and 57 women) were excluded due to gross hemolysis or lipemia. Individuals who were with previously diagnosed diabetes or on glucose-lowering therapy (132 men and 143 women) were removed from the analyses for 
biomarkers related to glucose metabolism, while participants on oral anti-hyperlipidemia (91 men and 135 women) were excluded from the analyses for biomarkers related to lipid metabolism.

Log-transformation was used to minimize the skewness in the analyses of fasting glucose, insulin, $\mathrm{HbA1C}$, HOMA-S, triglyceride, inflammatory markers, adiponectin and PAI-1. General linear model (GLM) was employed to analyze differences in the biomarkers according to the alcohol consumption categories by gender with adjustment for age, geographic location (north/ south), residential region (urban/rural), educational level ( $\leq 9$ or $>9$ y in school), smoking (current smoker/former smokers/no-smokers), physical activity (low/middle/ high), family income $(<20,000 / 20,000-39,999 / \geq 40,000$ $\mathrm{rmb} / \mathrm{y}$ ), family history of cardiovascular disease (CVD) or diabetes, BMI and diet (total energy intake without alcohol, energy adjusted dietary fiber and fat intake). Multinomial regression models were performed to assess the linear and nonlinear relationship between alcohol consumption and the dependent variables, using alcohol intake (g/day) as linear and quadratic terms, respectively. The multiple comparisons between different alcohol intake groups and abstainers were conducted using Dunnett's test.

The associations of alcohol consumption with the risk of having diabetes and combined diabetes and IFG were assessed by using multivariable logistic regression model with adjustment firstly for age (model 1 ) and then for other confounding factors (model 2). The adjustments included BMI, inflammation markers (log-transformed CRP, IL-6 and ferritin), adipokines (RBP4, log-transformed adiponectin and PAI-1) in the models 3, 4 and 5 , respectively. The multivariable analyses were further stratified by drinking frequency and beverage types. All analyses were conducted using Stata 9.2 (StataCorp, college station, Texas), and $P$ values $<0.05$ (two-side) were considered as statistical significance.

\section{Results}

\section{Characteristics of study participants according to alcohol consumption}

The characteristics of the study participants were summarized in Table 1 . Among men, 52.1\% were current drinkers and $15.3 \%$ consumed alcohol more than $40 \mathrm{~g} / \mathrm{d}$. Meanwhile, male drinkers were more likely to drink liquor and have alcohol more than 5 days per week, whereas only $9.8 \%$ female participants were current drinkers and majority of them seemed to be light, occasional and non-liquor drinkers. The proportion of drinkers was higher in Beijing (37.1\% vs. $20.1 \%, P<0.0001)$ and rural $(51.2 \%$ vs. $48.4 \%, P=0.05)$ than in Shanghai and urban areas, respectively. In men, alcohol drinking was positively associated with smoking, physically activity, blood pressure, energy and dietary fat intake, and was inversely associated with family income, BMI, dietary carbohydrate and fiber intake (all $P<0.05$ ). In women, drinkers tended to have higher family income and higher levels of BMI and energy intake.

\section{Associations of alcohol consumption with metabolic traits and cytokines}

Table 2 showed the relationships of alcohol intake with biomarkers of glucose and lipid metabolism, inflammation and adipokines. As expected, in men alcohol consumption was strongly and linearly associated with HDL and ferritin, the indicators of alcohol intake $[18,19]$ (both $P$ for linear trend $\leq 0.002$ ). However, it was not the case among women, which might be due to the small number of female drinkers in the study.

In the multivariable analyses among men, alcohol consumption was associated with increased RBP4 and ferritin, decreased insulin, HOMA-B and LDL in linear relations (All $P$ for linear trend $\leq 0.02$ ), and associated with insulin sensitivity in quadratic relation ( $P$ for quadratic trend $=0.05)$. Compared with non-drinkers, heavy drinkers have higher levels of glucose (5.68 vs. 5.49 $\mathrm{mmol} / \mathrm{l}, \mathrm{P}<0.05)$. In women, a positively linear association was observed between alcohol and RBP4 ( $P$ for linear trend $=0.005$ ).

\section{Associations of alcohol consumption with diabetes and IFG}

In general, alcohol consumption was not significantly associated with the risk of having diabetes in men. However, those of heavy and light male drinkers showed significantly higher risks of having combined diabetes and IFG (ORs 1.58 [95\%CI: 1.12-2.22] and 1.40 [95\%CI: 1.07-1.85], respectively), after adjustment for sociodemographic factors and lifestyles. In women, alcohol consumers showed a decreased risk (OR: 0.39, 95\% CI: 0.21-0.73) of having diabetes compared with abstainers (Table 3, model 2).

Further adjustment for BMI, inflammatory factors and adipokines did not appropriately alter the association between alcohol drinking and the reduced risk of having diabetes in both sexes. For men, the associations of low and high alcohol consumption with the risk of having combined diabetes and IFG were only slightly attenuated but still remained statistically significant (ORs 1.36 [95\%CI: 1.02-1.82] and 1.50 [95\%CI: 1.04-2.15], respectively).

When using different alcohol consumption categories as reference group, moderate alcohol consumption was found to be associated with a decreased risk of having diabetes and/or IFG compared with both of heavy (ORs 0.44[95\%CI: $0.22-0.91$ ] for diabetes and 0.53 [95\% CI: 0.33-0.86)] for combined diabetes and IFG) and light 
Table 1 Characteristics of participants according to alcohol consumption categories

\begin{tabular}{|c|c|c|c|c|c|c|c|c|}
\hline & \multicolumn{5}{|c|}{ Men } & \multicolumn{3}{|c|}{ Women } \\
\hline & Abstainers & $0.1-19.9 \mathrm{~g} / \mathrm{d}$ & $20.0-39.9 \mathrm{~g} / \mathrm{d}$ & $\geq 40.0 \mathrm{~g} / \mathrm{d}$ & $P$ value & Abstainers & $\geq 0.1 \mathrm{~g} / \mathrm{d}$ & $P$ value \\
\hline Participants, n (\%) & $688(47.9)$ & $386(26.9)$ & 142(9.9) & $219(15.3)$ & & 1635(90.2) & $177(9.8)$ & \\
\hline Age, y & $59.4(6.0)$ & $58.1(5.9)$ & $58.1(5.7)$ & $58.0(5.8)$ & 0.60 & $58.5(6.06)$ & $58.0(6.14)$ & 0.28 \\
\hline $\mathrm{BMI}, \mathrm{kg} / \mathrm{m}^{2}$ & $24.0(3.6)$ & $24.6(3.0)$ & $24.0(3.3)$ & $23.6(3.1)$ & 0.0029 & $24.7(3.7)$ & $25.3(3.9)$ & 0.05 \\
\hline Waistline, $\mathrm{cm}$ & $85.0(11.1)$ & $87.2(9.3)$ & $85.6(10.3)$ & $84.7(10.1)$ & 0.01 & $82.1(10.4)$ & $83.0(10.2)$ & 0.31 \\
\hline Systolic blood pressure, $\mathrm{mmHg}$ & $141.2(23.0)$ & $142.1(22.8)$ & $143.2(23.0)$ & $146.2(23.4)$ & 0.04 & $143.6(25.5)$ & $140.7(24.8)$ & 0.15 \\
\hline Alcohol intake, g/d & NA & $5.2(2.1,10.3)$ & $29.4(23.9,31.8)$ & $68.4(51.6,87.7)$ & $<0.0001$ & NA & $1.9(0.9,6.9)$ & NA \\
\hline Alcohol from liquor, g/d & NA & $3.0(0.9,5.3)$ & $15.4(11.7,19.1)$ & $59.8(56.8,62.8)$ & $<0.0001$ & NA & $2.6(2.3,3.6)$ & NA \\
\hline Alcohol from beer, g/d & NA & $2.4(0.3,4.5)$ & $9.0(5.6,12.4)$ & $19.1(16.4,21.8)$ & $<0.0001$ & NA & $3.4(2.9,3.8)$ & NA \\
\hline Alcohol from wine, g/d & NA & $1.4(3.4)$ & $4.4(9.2)$ & $6.0(15.5)$ & NA & $1.9(10.0)$ & $1.3(0.8,1.7)$ & NA \\
\hline Drinking frequency, $\%$ & & & & & $<0.0001$ & & & NA \\
\hline$<1$ day/wk & NA & 40.7 & 4.2 & 0.9 & & NA & 53.1 & \\
\hline 1-4 day/wk & NA & 29.5 & 21.1 & 9.1 & & NA & 22.6 & \\
\hline 5-7 day/wk & NA & 29.8 & 74.7 & 90.0 & & NA & 24.3 & \\
\hline Drinking pattern, \% & & & & & $<0.0001$ & & & NA \\
\hline Liquor drinkers & NA & 43.0 & 56.3 & 75.3 & & NA & 22.6 & \\
\hline Non-liquor drinkers & NA & 57.0 & 43.7 & 24.7 & & NA & 77.4 & \\
\hline North residence, \% & 38.8 & 66.8 & 56.3 & 55.7 & $<0.0001$ & 45.9 & 78.0 & $<0.0001$ \\
\hline Rural, \% & 51.7 & 40.2 & 52.8 & 67.1 & $<0.0001$ & 51.0 & 34.5 & $<0.0001$ \\
\hline Education $>9$ years, $\%$ & 29.5 & 36.0 & 24.7 & 15.5 & $<0.0001$ & 18.4 & 20.9 & 0.41 \\
\hline High physical activity level, \% & 49.7 & 56.5 & 66.2 & 65.3 & $<0.0001$ & 47.0 & 46.3 & 0.67 \\
\hline Family income, \% & & & & & $<0.0001$ & & & 0.0002 \\
\hline$<20,000 \mathrm{rmb} / \mathrm{y}$ & 30.3 & 21.5 & 26.8 & 38.6 & & 27.7 & 16.4 & \\
\hline 20,000-39,999 rmb/y & 58.4 & 61.4 & 62.7 & 54.5 & & 61.4 & 64.4 & \\
\hline$\geq 40,000 \mathrm{rmb} / \mathrm{y}$ & 11.3 & 17.1 & 10.5 & 6.8 & & 10.9 & 19.2 & \\
\hline Current smoker, \% & 44.6 & 56.2 & 69.0 & 81.7 & $<0.0001$ & 4.3 & 15.8 & $<0.0001$ \\
\hline Family history of CVD or diabetes, \% & 28.8 & 40.4 & 23.2 & 25.1 & $<0.0001$ & 30.8 & 40.7 & 0.0075 \\
\hline \multicolumn{9}{|l|}{ Nutrients * } \\
\hline Energy, kcal/day & $2553(855)$ & $2622(833)$ & $2856(796)$ & 3297 (1018) & $<0.0001$ & $2018(566)$ & $2212(655)$ & $<0.0001$ \\
\hline Energy without alcohol, kcal/day & 2553(855) & 2576(829) & 2663(798) & 2714(892) & 0.07 & 2018(566) & $2158(647)$ & $<0.0001$ \\
\hline Fat, g/day & $74.4(25.7)$ & $82.0(25.9)$ & $83.1(27.0)$ & $84.1(27.8)$ & $<0.0001$ & $66.8(19.2)$ & $74.5(17.9)$ & $<0.0001$ \\
\hline Protein, g/day & $81.5(18.2)$ & $88.0(18.2)$ & $87.8(20.4)$ & $86.4(19.9)$ & $<0.0001$ & $65.0(14.2)$ & $70.5(12.7)$ & $<0.0001$ \\
\hline Carbohydrate, g/day & $413.2(66.0)$ & $392.4(65.6)$ & $389.7(70.4)$ & $389.0(70.1)$ & $<0.0001$ & $305.0(48.2)$ & $284.8(42.8)$ & $<0.0001$ \\
\hline Fiber, g/day & $13.9(5.8)$ & $16.2(6.8)$ & $14.9(5.3)$ & $13.8(5.6)$ & $<0.0001$ & $12.6(4.9)$ & $14.8(5.5)$ & $<0.0001$ \\
\hline
\end{tabular}

NA: Not applicable.

Data are means (SD) or median (inter-quartile range) where appropriate.

* All the nutrients are energy adjusted using residual regression method.

alcohol consumption (OR 0.59 [95\%CI: 0.38-0.91] for combined diabetes and IFG) (Additional file 1).

\section{Associations of drinking frequency and beverage type with diabetes and IFG}

In men, the associations of alcohol intake with diabetes and combined diabetes and IFG were analyzed based upon the categorized beverage type and drinking frequency. Those who drunk more than 5 day per week were further stratified according to the levels of alcohol intake (Table 4). A decreased risk (OR: 0.61, 95\%CI: 0.37-0.98) of having combined diabetes and IFG was observed among moderate drinkers compared with abstainers after controlling for all of the covariates, whereas an increased risk was observed among light and heavy drinkers. In the stratified analyses according to beverage types, liquor drinkers had a higher likelihood of having combined diabetes and IFG in the full model analysis (OR: 1.47, 95\%CI: 1.09-1.98), and the increased risk was mainly observed in light and heavy liquor drinkers compared with abstainers. There was no association observed among non-liquor drinkers.

\section{Discussion}

In the present study, among men both high and low alcohol consumptions were associated with a higher 
Table 2 Adjusted means of metabolic traits and markers of inflammation and adipokines according to alcohol consumption categories

\begin{tabular}{|c|c|c|c|c|c|c|c|c|c|c|}
\hline \multirow[b]{2}{*}{ Biomarkers } & \multicolumn{4}{|c|}{ Men } & \multirow[b]{2}{*}{$\begin{array}{l}P \text { for } \\
\text { linear } \\
\text { trend * }\end{array}$} & \multirow[b]{2}{*}{$\begin{array}{c}P \text { for } \\
\text { quadratic } \\
\text { trend } t\end{array}$} & \multicolumn{2}{|c|}{ Women } & \multirow[b]{2}{*}{$\begin{array}{c}P \text { for } \\
\text { linear } \\
\text { trend } \\
*\end{array}$} & \multirow[b]{2}{*}{$\begin{array}{c}P \text { for } \\
\text { quadratic } \\
\text { trendt }\end{array}$} \\
\hline & Abstainers & $\begin{array}{c}0.1-19.9 \mathrm{~g} / \\
\mathrm{d}\end{array}$ & $\begin{array}{c}20.0-39.9 \mathrm{~g} / \\
\mathrm{d}\end{array}$ & $\geq 40.0 \mathrm{~g} / \mathrm{d}$ & & & Abstainers & $>0.1 \mathrm{~g} / \mathrm{d}$ & & \\
\hline $\begin{array}{l}\text { Fasting glucose, } \\
\mathrm{mmol} / \mathrm{l}\end{array}$ & $5.49(0.05)$ & $5.58(0.06)$ & $5.47(0.09)$ & $5.68(0.08) \S$ & 0.10 & 0.93 & $5.45(0.07)$ & $5.48(0.09)$ & 0.40 & 0.66 \\
\hline Insulin, $\mu \mathrm{U} / \mathrm{ml}$ & $12.86(0.34)$ & $12.45(0.42)$ & $10.88(0.52) \S$ & $\begin{array}{l}11.38 \\
(0.48) \S\end{array}$ & 0.02 & 0.06 & $15.13(0.55)$ & $\begin{array}{l}14.83 \\
(0.71)\end{array}$ & 0.33 & 0.54 \\
\hline $\mathrm{A} 1 \mathrm{C}, \%$ & $5.80(0.04)$ & $5.74(0.04)$ & $5.68(0.06)$ & $5.74(0.06)$ & 0.62 & 0.08 & $5.80(0.05)$ & $5.76(0.07)$ & 0.59 & 0.46 \\
\hline HOMA-S, \% & $67.9(1.8)$ & $70.2(2.4)$ & 80.5 (3.9)‡ & $76.3(3.2) \S$ & 0.27 & 0.05 & $58.5(2.1)$ & $59.3(2.8)$ & 0.41 & 0.62 \\
\hline HOMA-B, \% & $111.9(2.3)$ & $103.7(2.9) \S$ & $99.5(4.1) \S$ & 97.3 (3.6)‡ & 0.008 & 0.14 & $124.5(3.5)$ & $121.8(4.6)$ & 0.16 & 0.37 \\
\hline $\mathrm{HDL}, \mathrm{mmol} / \mathrm{l}$ & $1.17(0.02)$ & $1.20(0.02)$ & $1.30(0.03) \neq$ & $1.36(0.02) \neq$ & $\begin{array}{c}< \\
0.0001\end{array}$ & 0.03 & $1.30(0.02)$ & $1.33(0.03)$ & 0.99 & 0.88 \\
\hline $\mathrm{LDL}, \mathrm{mmol} / \mathrm{l}$ & $3.12(0.04)$ & $3.05(0.05)$ & $3.05(0.08)$ & $2.92(0.07) \S$ & 0.02 & 0.17 & $3.24(0.07)$ & $3.30(0.10)$ & 0.17 & 0.49 \\
\hline Triglyceride, mmol// & $1.15(0.03)$ & $1.17(0.04)$ & $1.09(0.06)$ & $1.05(0.05)$ & 0.22 & 0.64 & $1.26(0.05)$ & $1.18(0.07)$ & 0.77 & 0.65 \\
\hline CRP, mg/l & $0.76(0.04)$ & $0.71(0.05)$ & $0.70(0.07)$ & $0.66(0.06)$ & 0.55 & 0.80 & $0.69(0.05)$ & $0.61(0.06)$ & 0.17 & 0.14 \\
\hline $\mathrm{IL}-6, \mathrm{pg} / \mathrm{ml}$ & $1.09(0.04)$ & $0.97(0.05)$ & $1.16(0.08)$ & $1.05(0.07)$ & 0.43 & 0.50 & $1.02(0.06)$ & $0.95(0.07)$ & 0.46 & 0.58 \\
\hline Ferritin, $\mu \mathrm{g} / \mathrm{ml}$ & $152.5(4.6)$ & $156.7(5.9)$ & $165.9(9.3)$ & $170.9(8.3) \S$ & 0.002 & 0.25 & $106.9(4.5)$ & $107.5(6.1)$ & 0.53 & 0.61 \\
\hline $\mathrm{RBP} 4, \mathrm{ng} / \mathrm{ml}$ & $40.4(0.6)$ & $44.1(0.7) \ddagger$ & $44.4(1.1) \neq$ & 46.4 (0.9)‡ & $\begin{array}{c}< \\
0.0001\end{array}$ & $<0.0001$ & $39.0(0.8)$ & $41.5(1.1) \ddagger$ & 0.005 & 0.01 \\
\hline Adiponectin, $\mu \mathrm{g} / \mathrm{ml}$ & $12.2(0.5)$ & $12.4(0.6)$ & $12.4(0.9)$ & $11.5(0.7)$ & 0.28 & 0.63 & $13.2(0.7)$ & $13.7(1.0)$ & 0.48 & 0.66 \\
\hline $\mathrm{PAl}-1, \mathrm{ng} / \mathrm{ml}$ & $2.73(0.42)$ & $4.20(0.81)$ & $1.77(0.51)$ & $4.67(1.16)$ & 0.32 & 0.54 & $5.39(1.16)$ & $6.26(1.86)$ & 0.17 & 0.06 \\
\hline
\end{tabular}

Data are means (SE) or geometric means (SE) adjusted for age, geographic location (north/south), residential region (urban/rural), educational level, smoking, physical activity, family income, family history of CVD or diabetes, BMI and diet (total energy intake without alcohol, energy adjusted dietary fiber and fat intake). Participants who were previously diagnosed diabetes or on glucose-lowering therapy (men: $n=132 ;$ women: $n=143$ ) were excluded from the analyses for diabetes-associated traits, and those who were on oral anti-hyperlipidemia (men: $n=91$; women: $n=135$ ) were excluded from the analyses for lipid profiles.

* $P$ values are from analyses the model alcohol consumption $(\mathrm{g} / \mathrm{d})$ as linear terms.

$+P$ values are from analyses the model alcohol consumption $(\mathrm{g} / \mathrm{d})$ as quadratic terms.

$\neq P<0.001$ compared with abstainers.

$\S P<0.05$ compared with abstainers.

Table 3 Odds ratios (95\% confidence intervals) for diabetes and combined diabetes and IFG according to alcohol consumption categories

\begin{tabular}{|c|c|c|c|c|c|c|c|}
\hline & & \multicolumn{4}{|c|}{ Men } & \multicolumn{2}{|c|}{ Women } \\
\hline & & Abstainers & $0.1-19.9 \mathrm{~g} / \mathrm{d}$ & $20.0-39.9 \mathrm{~g} / \mathrm{d}$ & $\geq 40.0 \mathrm{~g} / \mathrm{d}$ & Abstainers & $\geq 0.1 \mathrm{~g} / \mathrm{d}$ \\
\hline \multirow[t]{6}{*}{ Diabetes } & cases/non-cases, n & $95 / 593$ & $74 / 312$ & $13 / 129$ & $32 / 187$ & $206 / 1429$ & $12 / 165$ \\
\hline & Model 1 & 1.0 (reference) & $1.53(1.09,2.14)$ & $0.65(0.35,1.20)$ & $1.11(0.72,1.71)$ & 1.0 (reference) & $0.51(0.28,0.94)$ \\
\hline & Model 2 & 1.0 (reference) & $1.25(0.87,1.79)$ & $0.72(0.38,1.37)$ & $1.57(0.97,2.54)$ & 1.0 (reference) & $0.39(0.21,0.73)$ \\
\hline & Model 3 & 1.0 (reference) & $1.26(0.88,1.81)$ & $0.74(0.39,1.40)$ & $1.61(0.99,2.60)$ & 1.0 (reference) & $0.39(0.21,0.73)$ \\
\hline & Model 4 & 1.0 (reference) & $1.30(0.90,1.89)$ & $0.69(0.36,1.32)$ & $1.56(0.96,2.53)$ & 1.0 (reference) & $0.42(0.22,0.78)$ \\
\hline & Model 5 & 1.0 (reference) & $1.27(0.87,1.86)$ & $0.70(0.37,1.35)$ & $1.59(0.96,2.61)$ & 1.0 (reference) & $0.41(0.22,0.78)$ \\
\hline \multirow[t]{6}{*}{ Combined diabetes and IFG } & cases/non-cases, n & $270 / 418$ & $211 / 175$ & $52 / 90$ & 107/112 & $596 / 1039$ & $75 / 102$ \\
\hline & Model 1 & 1.0 (reference) & $1.86(1.44,2.39)$ & $0.89(0.61,1.29)$ & $1.47(1.08,2.00)$ & 1.0 (reference) & $1.31(0.96,1.80)$ \\
\hline & Model 2 & 1.0 (reference) & $1.40(1.07,1.85)$ & $0.81(0.54,1.20)$ & $1.58(1.12,2.22)$ & 1.0 (reference) & $0.97(0.69,1.36)$ \\
\hline & Model 3 & 1.0 (reference) & $1.42(1.07,1.87)$ & $0.82(0.55,1.23)$ & $1.64(1.16,2.33)$ & 1.0 (reference) & $0.98(0.70,1.38)$ \\
\hline & Model 4 & 1.0 (reference) & $1.38(1.03,1.84)$ & $0.77(0.51,1.16)$ & $1.47(1.03,2.10)$ & 1.0 (reference) & $1.03(0.72,1.47)$ \\
\hline & Model 5 & 1.0 (reference) & $1.36(1.02,1.82)$ & $0.80(0.53,1.22)$ & $1.50(1.04,2.15)$ & 1.0 (reference) & $1.03(0.72,1.47)$ \\
\hline
\end{tabular}

Model 1: Adjusted for age

Model 2: Adjusted for age, geographic location (north/south), residential region (urban/rural), educational level, smoking, physical activity, family income, family history of CVD or diabetes, and diet (total energy intake without alcohol, energy adjusted dietary fiber and fat intake).

Model 3: Adjusted variables in model 2 plus BMI

Model 4: Adjusted variables in model 3 plus inflammatory markers (log-transformed CRP, IL-6 and ferritin)

Model 5: Adjusted variables in model 4 plus adipokines (RBP4, log-transformed adiponectin and PAI-1) 
Table 4 Odds ratios (95\% confidence intervals) for diabetes and combined diabetes and IFG in men according to the categories of drinking frequency and types of beverage

\begin{tabular}{|c|c|c|c|c|}
\hline & & Participants (n) & Diabetes & Combined diabetes and IFG \\
\hline \multicolumn{5}{|c|}{ Drinking frequency } \\
\hline Abstainers & & 688 & 1.0 (reference) & 1.0 (reference) \\
\hline$<1$ day/wk & & 165 & $1.17(0.71,1.92)$ & $1.45(0.99,2.13)$ \\
\hline 1-4 day/wk & & 164 & $1.22(0.73,2.05)$ & $1.27(0.86,1.88)$ \\
\hline \multirow[t]{3}{*}{ 5-7 day/wk } & $0.1-19.9 \mathrm{~g} / \mathrm{d}$ & 115 & $1.24(0.70,2.21)$ & $1.59(1.02,2.48)$ \\
\hline & $20-39.9 \mathrm{~g} / \mathrm{d}$ & 106 & $0.72(0.36,1.46)$ & $0.61(0.37,0.98)$ \\
\hline & $\geq 40.0 \mathrm{~g} / \mathrm{d}$ & 197 & $1.72(1.03,2.87)$ & $1.50(1.02,2.18)$ \\
\hline \multicolumn{5}{|l|}{ Beverage type } \\
\hline Abstainers & & 688 & 1.0 (reference) & 1.0 (reference) \\
\hline \multicolumn{5}{|c|}{ Liquor drinkers } \\
\hline & $0.1-19.9 \mathrm{~g} / \mathrm{d}$ & 166 & $1.60(0.99,2.61)$ & $1.85(1.24,2.77)$ \\
\hline & $20-39.9 \mathrm{~g} / \mathrm{d}$ & 80 & $0.95(0.44,2.03)$ & $0.92(0.55,1.56)$ \\
\hline & $\geq 40.0 \mathrm{~g} / \mathrm{d}$ & 165 & $1.52(0.86,2.68)$ & $1.49(1.00,2.23)$ \\
\hline & Total & 411 & $1.43(0.96,2.12)$ & $1.47(1.09,1.98)$ \\
\hline \multicolumn{5}{|c|}{ Non-liquor drinkers } \\
\hline & $0.1-19.9 \mathrm{~g} / \mathrm{d}$ & 220 & $1.07(0.68,1.70)$ & $1.11(0.78,1.56)$ \\
\hline & $20-39.9 \mathrm{~g} / \mathrm{d}$ & 62 & $0.40(0.12,1.34)$ & $0.68(0.36,1.25)$ \\
\hline & $\geq 40.0 \mathrm{~g} / \mathrm{d}$ & 54 & $1.92(0.87,4.23)$ & $1.64(0.88,3.03)$ \\
\hline & Total & 336 & $1.05(0.70,1.58)$ & $1.08(0.80,1.46)$ \\
\hline
\end{tabular}

Data were adjusted for age, geographic location (Beijing/Shanghai), residential region (urban/rural), educational level, smoking, physical activity, family income, family history of CVD or diabetes, diet (total energy intake without alcohol, energy adjusted dietary fiber and fat intake), BMI, inflammatory markers (logtransformed CRP, IL-6 and ferritin), adipokines (RBP4, log-transformed adiponectin and PAI-1).

risk, whereas moderate alcohol consumption with weekly drinking frequency over 5 days was associated with a lower risk of having combined diabetes and IFG. The associations were independent of lifestyle factor, inflammatory markers and adipokines. Among women, alcohol consumption was inversely associated with the risk of diabetes. To our knowledge, this is the first study investigating the associations of alcohol consumption with risks of diabetes mellitus and combined diabetes and IFG with simultaneously considering the modifying effects of drinking frequency, beverage types, as well as adipokines and markers of inflammation among Chinese people.

Previously, protective effects of moderate drinking on the development of diabetes have been observed in a large number of epidemiological studies [4,20-22]. For instance, a meta-analysis including 13 cohorts indicated moderate alcohol intake decreased the risk for diabetes by $28 \%$ [2]. However, unlike findings from previous studies, the favorable effect of moderate drinking was only evidenced when compared with heavy drinkers but not with abstainers in our study. Additionally, among men we found a reduced risk for combined diabetes and IFG in moderate drinkers with the highest level of drinking frequency. Due to the small sample size in the subgroup, it remains to be elucidated whether moderate alcohol consumption with lower drinking frequency also has favorable impact. Among women, alcohol intake was associated with a decreased risk of having diabetes mellitus but not with combined diabetes and IFG. This disparity might be explained by the limited sample size and unclear drinking pattern.

In the majority of prospective studies, high alcohol consumption increased the risk of type 2 diabetes compared to moderate drinkers. However, the association was inconsistent when compared to abstainers [2]. In this study, we observed an adverse effect among heavy drinkers compared with both moderate drinkers and abstainers. Similar effects were also found among light drinkers in disagreement with previous studies $[2,3]$. In previous studies, the benefit effects of alcohol on diabetes were more apparent among those who consumed wine and beer, whereas liquor drinking were suggested to have unfavorable effect $[23,24]$. In line with these studies, we observed that an increased risk of combined diabetes and IFG was associated with light and heavy liquor drinking but not with non-liquor drinking. Given the fact of much higher proportion of liquor drinkers in Chinese than in Caucasian [25], the controversial results between our study and others might be attributable to the differences in the types of beverage consumption. Moreover, drinking frequency might also modify the association between alcohol consumption and diabetes. In the stratified analyses, individuals drinking less than $1 \mathrm{~d} /$ wk tended to have a higher risk of combined diabetes and IFG. Although the majority subjects in this 
group were light and non-liquor drinkers, we could not rule out the possibility that some of them consumed excessive alcohol over a short period of time. Interestingly, inconsistent with previous reports [23], the increased risk was also observed in regular light drinkers (5-7 d/wk, 0.1-19.9 g/d). Given the cross-sectional design, it is unclear whether some of the individuals have recently changed drinking habit according to their health conditions. Certainly, prospective studies are needed to address this issue.

It has been suggested that the association between alcohol consumption and disease such as type 2 diabetes might be attributed to other lifestyle factors [26]. However, a large prospective study indicated that the associations do not seem to be confounded by other lifestyle behaviors [27]. Interestingly, in our study, male heavy drinkers appeared to have the lowest socioeconomic status (SES) indicated by lower educational attainment and family income. They were also more likely to have unhealthy lifestyles such as cigarette smoking, consuming more dietary fat and less fiber intake. However, controlling these confounding factors did not largely attenuate the association between alcohol consumption and combined diabetes and IFG, suggesting that effect of alcohol intake was independent of other lifestyle factors.

In line with previous studies $[9,28]$, we found a higher level of insulin sensitivity index among male drinker compared to abstainers, reaching its peak in moderate alcohol intake, and also observed an inverse association between alcohol intake and beta-cell function after multiple adjustment, although no such effects were detected among female drinkers who were mostly light drinkers. Mechanistic linking between the levels of alcohol intake and pathogeneses of diabetes mellitus are rather complicated and has not been fully elucidated. Nonetheless, existing data from observational $[29,30]$ and/or intervention studies [7,9] suggested that moderate drinking was associated with increased insulin sensitivity, whereas high alcohol intake showed no or even opposite effects. Studies in vitro and in vivo also indicated toxic effects of alcohol on pancreatic islet cells as well as inhibition of insulin secretion [31,32]. Recently, Crandall JP et al. reported that alcohol consumption was associated with lower insulin secretion based upon the results of a longterm interventional trial [28]. Taken together, the Ushaped relationship between the levels of alcohol intake and the risk of type 2 diabetes might be explained by altered insulin sensitivity and impaired beta-cell function.

Obesity, chronic inflammation and certain adipokines have been proposed to be the mediators for the association between alcohol intake and diabetes [33]. However, we only observed a minor alteration in the associations between alcohol intake and risks of having diabetes or
IFG following adjustment for BMI, adipokines and markers of inflammation, implicating that these factors might not be essential players, at least in our study population. Meanwhile, one of the novel findings in our study is the strong positive linear association between plasma RBP4 concentration and alcohol intake in both sexes. Indeed, Fernandez-Real JM et al. recently found a positive correlation between serum RBP4 and ferritin from a cross-sectional study. In addition, they also reported that iron depletion intervention reduced serum RBP4 concentration in diabetic patients [34]. Considering the close association between alcohol consumption and elevated ferritin in our and other studies [19], the positive correlation between RBP4 and alcohol consumption might be, at least partially, explained by raised iron storage.

There were some limitations in our study. Firstly, alcohol consumption and drinking frequency were evaluated by questionnaire, which might induce recall bias. Nevertheless, the dose-response relationships between alcohol consumption and alcohol related biomarkers such as HDL and ferritin, suggested the validity of our questionnaire for the assessment of alcohol intake. Secondly, the cross-sectional nature of the current study could not allow us to establish any causal relationship. Thirdly, due to lacking of relevant data, we could not exclude former drinkers from abstainers, which might confound the observed associations between alcohol consumption and risk of having altered glucose metabolism. However, according to the data from a large cohort study conducted in 66,743 Chinese men in Shanghai [35], only $5.3 \%$ of abstainers were former drinkers. Likewise, the biases driven by misclassifying former drinkers in abstainers might be negligible. Fourthly, we could not distinguish individuals with type 1 diabetes from those with type 2 diabetes. Given that in the present study only $14.4 \%$ of diabetic individuals had a diagnosis when they were younger than 50 years, and the fraction of type 1 diabetes is less than $10 \%$ among diabetic patients, it is less likely that the associations of alcohol consumption and diabetic risk could be confounded with the autoimmune diabetes. Obviously, further prospective studies with larger sample size are needed to establish casual role of alcohol intake in pathogenesis of diabetes mellitus.

\section{Conclusions}

In our study, an approximate J-shaped association was observed between alcohol consumption and combined diabetes and IFG among Chinese men, while alcohol intake in women was associated with a reduced risk of having diabetes. Obviously, more studies are needed to clarify the role of alcohol intake and mechanism(s) involving in the pathogenesis of diabetes mellitus. 


\section{Additional material}

Additional file 1: Multivariable adjusted odds ratios $(95 \%$ confidence intervals) for diabetes mellitus and combined diabetes and IFG according to alcohol consumption categories. This table presented the associations of alcohol consumption with the risk of having diabetes and combined diabetes and IFG, using different alcohol consumption categories as reference group.

\section{Acknowledgements}

We are grateful to all the individuals who participated in the Nutrition and Health of Aging Population in China Study, as well as our colleagues and collaborators from the local Centers for Disease Control and Prevention of Beijing and Shanghai.

This study was funded by the research grants from the Chief Scientist Program of Shanghai Institutes for Biological Sciences, Chinese Academy of Sciences (SIBS2008006), the National Natural Science Foundation of China (30930081), National High Technology Research and Development Program (863 Program) (2009AA022704).

\section{Authors' contributions}

$\mathrm{CL}$ performed the statistical analysis and drafted the manuscript. ZY participated in the data analyses, drafting and revising the manuscript. $\mathrm{HL}$, JW, LS and QB carried out the measurements of metabolic traits and cytokines. $\mathrm{XL}$, as the principal investigator for the project of the Nutrition and Health of Aging Population in China, contributed to the scientific ideas, grant application, study design, result interpretation and revised the manuscript critically. All authors have read and approved the manuscript.

\section{Competing interests}

The authors declare that they have no competing interests.

Received: 1 June 2010 Accepted: 19 November 2010 Published: 19 November 2010

\section{References}

1. Yang W, Lu J, Weng J, Jia W, Ji L, Xiao J, et al: Prevalence of diabetes among men and women in China. N Engl J Med 2010, 362:1090-1101.

2. Carlsson S, Hammar N, Grill V: Alcohol consumption and type 2 diabetes Meta-analysis of epidemiological studies indicates a U-shaped relationship. Diabetologia 2005, 48:1051-1054.

3. Koppes LL, Dekker JM, Hendriks HF, Bouter LM, Heine RJ: Moderate alcohol consumption lowers the risk of type 2 diabetes: a meta-analysis of prospective observational studies. Diabetes Care 2005, 28:719-725.

4. Beulens JW, Stolk RP, van der Schouw YT, Grobbee DE, Hendriks HF, Bots ML: Alcohol consumption and risk of type 2 diabetes among older women. Diabetes Care 2005, 28:2933-2938

5. Waki K, Noda M, Sasaki S, Matsumura Y, Takahashi Y, Isogawa A, et al: Alcohol consumption and other risk factors for self-reported diabetes among middle-aged Japanese: a population-based prospective study in the JPHC study cohort I. Diabet Med 2005, 22:323-331.

6. Schooling CM, Jiang CQ, Lam TH, Zhang WS, Cheng KK, Leung GM: Alcohol use and fasting glucose in a developing southern Chinese population: the Guangzhou Biobank Cohort Study. J Epidemiol Community Health 2009, 63:121-127.

7. Davies MJ, Baer DJ, Judd JT, Brown ED, Campbell WS, Taylor PR: Effects of moderate alcohol intake on fasting insulin and glucose concentrations and insulin sensitivity in postmenopausal women: a randomized controlled trial. JAMA 2002, 287:2559-2562.

8. Imhof A, Froehlich M, Brenner H, Boeing H, Pepys MB, Koenig W: Effect of alcohol consumption on systemic markers of inflammation. Lancet 2001 357:763-767

9. Sierksma A, Patel H, Ouchi N, Kihara S, Funahashi T, Heine RJ, et al: Effect of moderate alcohol consumption on adiponectin, tumor necrosis factoralpha, and insulin sensitivity. Diabetes Care 2004, 27:184-189.

10. Freeman DJ, Norrie J, Caslake MJ, Gaw A, Ford I, Lowe GD, et al: C-reactive protein is an independent predictor of risk for the development of diabetes in the West of Scotland Coronary Prevention Study. Diabetes 2002, 51:1596-1600.

11. Li S, Shin HJ, Ding EL, van Dam RM: Adiponectin levels and risk of type 2 diabetes: a systematic review and meta-analysis. JAMA 2009, 302:179-188.

12. Ye $X, Y u Z$, Li H, Franco OH, Liu Y, Lin X: Distributions of C-reactive protein and its association with metabolic syndrome in middle-aged and older Chinese people. J Am Coll Cardiol 2007, 49:1798-1805.

13. Zhao W, Hasegawa $K$, Chen J: The use of food-frequency questionnaires for various purposes in China. Public Health Nutr 2002, 5:829-833.

14. Yang Y: Chinese Food Composition Table 2004. Peking University Medical Press; 200526

15. Sun L, Franco OH, Hu FB, Cai L, Yu Z, Li H, et al: Ferritin concentrations, metabolic syndrome, and type 2 diabetes in middle-aged and elderly chinese. J Clin Endocrinol Metab 2008, 93:4690-4696.

16. Levy JC, Matthews DR, Hermans MP: Correct homeostasis model assessment (HOMA) evaluation uses the computer program. Diabetes Care 1998, 21:2191-2192.

17. Alberti KG, Zimmet PZ: Definition, diagnosis and classification of diabetes mellitus and its complications. Part 1: diagnosis and classification of diabetes mellitus provisional report of a WHO consultation. Diabet Med 1998, 15:539-553.

18. Szegedi A, Muller MJ, Himmerich H, Anghelescu I, Wetzel H: Carbohydratedeficient transferrin (CDT) and HDL cholesterol (HDL) are highly correlated in male alcohol dependent patients. Alcohol Clin Exp Res 2000, 24:497-500.

19. Whitfield JB, Zhu G, Heath AC, Powell And LW, Martin NG: Effects of alcohol consumption on indices of iron stores and of iron stores on alcohol intake markers. Alcohol Clin Exp Res 2001, 25:1037-1045.

20. Carlsson S, Hammar N, Grill V, Kaprio J: Alcohol consumption and the incidence of type 2 diabetes: a 20-year follow-up of the Finnish twin cohort study. Diabetes Care 2003, 26:2785-2790.

21. Diem P, Deplazes M, Fajfr R, Bearth A, Muller B, Christ ER, et al: Effects of alcohol consumption on mortality in patients with Type 2 diabetes mellitus. Diabetologia 2003, 46:1581-1585.

22. Wei M, Gibbons LW, Mitchell TL, Kampert JB, Blair SN: Alcohol intake and incidence of type 2 diabetes in men. Diabetes Care 2000, 23:18-22.

23. Conigrave KM, Hu BF, Camargo CA, Stampfer MJ, Willett WC, Rimm EB: A prospective study of drinking patterns in relation to risk of type 2 diabetes among men. Diabetes 2001, 50:2390-2395.

24. Hodge AM, English DR, O'Dea K, Giles GG: Alcohol intake, consumption pattern and beverage type, and the risk of Type 2 diabetes. Diabet Med 2006, 23:690-697.

25. Sieri S, Agudo A, Kesse E, Klipstein-Grobusch K, San-Jose B, Welch AA, et al: Patterns of alcohol consumption in 10 European countries participating in the European Prospective Investigation into Cancer and Nutrition (EPIC) project. Public Health Nutr 2002, 5:1287-1296.

26. Fillmore KM, Stockwell T, Chikritzhs T, Bostrom A, Kerr W: Moderate alcohol use and reduced mortality risk: systematic error in prospective studies and new hypotheses. Ann Epidemiol 2007, 17:S16-S23.

27. Joosten MM, Grobbee DE, van der AD, Verschuren WM, Hendriks HF, Beulens JW: Combined effect of alcohol consumption and lifestyle behaviors on risk of type 2 diabetes. Am J Clin Nutr 2010, 91:1777-1783.

28. Crandall JP, Polsky S, Howard AA, Perreault L, Bray GA, Barrett-Connor E, et al: Alcohol consumption and diabetes risk in the Diabetes Prevention Program. Am J Clin Nutr 2009, 90:595-601.

29. Greenfield JR, Samaras K, Jenkins AB, Kelly PJ, Spector TD, Campbell LV: Moderate alcohol consumption, estrogen replacement therapy, and physical activity are associated with increased insulin sensitivity: is abdominal adiposity the mediator? Diabetes Care 2003, 26:2734-2740.

30. Bell RA, Mayer-Davis EJ, Martin MA, D'Agostino RB, Haffner SM: Associations between alcohol consumption and insulin sensitivity and cardiovascular disease risk factors: the Insulin Resistance and Atherosclerosis Study. Diabetes Care 2000, 23:1630-1636.

31. Koko V, Todorovic V, Nikolic JA, Glisic R, Cakic M, Lackovic V, et al: Rat pancreatic B-cells after chronic alcohol feeding. A morphometric and fine structural study. Histol Histopathol 1995, 10:325-337.

32. Dembele $K$, Nguyen KH, Hernandez TA, Nyomba BL: Effects of ethanol on pancreatic beta-cell death: interaction with glucose and fatty acids. Cell Biol Toxicol 2009, 25:141-152.

33. Beulens JW, Rimm EB, Hu FB, Hendriks HF, Mukamal KJ: Alcohol consumption, mediating biomarkers, and risk of type 2 diabetes among middle-aged women. Diabetes Care 2008, 31:2050-2055. 
34. Fernandez-Real JM, Moreno JM, Ricart W: Circulating retinol-binding protein-4 concentration might reflect insulin resistance-associated iron overload. Diabetes 2008, 57:1918-1925.

35. Xu WH, Zhang XL, Gao YT, Xiang YB, Gao LF, Zheng W, et al: Joint effect of cigarette smoking and alcohol consumption on mortality. Prev Med 2007, 45:313-319.

\section{Pre-publication history}

The pre-publication history for this paper can be accessed here: http://www.biomedcentral.com/1471-2458/10/713/prepub

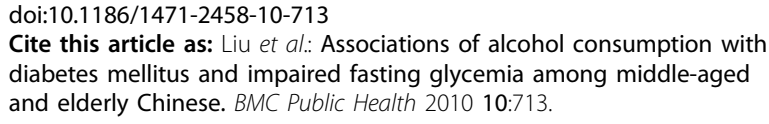

Cite this article as: Liu et al:: Associations of alcohol consumption with diabetes mellitus and impaired fasting glycemia among middle-aged and elderly Chinese. BMC Public Health 2010 10:713.

\section{Submit your next manuscript to BioMed Central} and take full advantage of:

- Convenient online submission

- Thorough peer review

- No space constraints or color figure charges

- Immediate publication on acceptance

- Inclusion in PubMed, CAS, Scopus and Google Scholar

- Research which is freely available for redistribution

Submit your manuscript at www.biomedcentral.com/submit
C Biomed Central 